\title{
Rescue of a saturation diver, unconscious due to an explosion underwater
}

\author{
Ajit C. Kulkarni
}

Medical Centre, Mumbai, India

\begin{abstract}
Evolution of "safe diving practices" introduced by the diving industry and regulatory authorities in the North Sea over the past 3 or 4 decades has improved the safety records of oilfield commercial diving considerably. However, accidents still occur. In an accident occurring underwater, the outcome is often fatal. For a diving doctor providing emergency medical advice to the industry, when a diving superintendent calls to say "I have a problem" indicates an emergency and a life and death situation for a diver in water. Making a quick decision after comprehending the situations is important to tackle the problem.
\end{abstract}

(Int Marit Health 2021; 72, 1: 46-48)

Key words: saturation diving, oxy-arc cutting, underwater explosion, hypothermia

\section{INTRODUCTION}

During diving nitrogen from compressed air dissolves in blood. While surfacing this dissolved nitrogen is expelled out of the blood during expiration at decompression stop. Any violation in this would result in decompression sickness to the diver. Beyond a depth of 30-40 m, nitrogen produces a narcotic effect and for deeper dives, nitrogen is replaced by helium, another inert gas. Quantity of inert gas dissolving in blood is a depth-time relationship and beyond a certain time no more gas can be dissolved in blood, i.e. blood is fully saturated. Under this condition, time under compression can increase indefinitely but the time for decompression remains constant. This technique known as saturation diving is used extensively in offshore oilfield diving operations for carrying out inspection, maintenance, repair of underwater structures which is carried out from specially constructed vessels. Depending on the size of the vessel, 12-24 divers remain under elevated atmospheric pressure in habitats. Depending on the depth of the oil field, divers are at different storage depths so that the entire length of offshore structure can be attended to. From each depth, limits of upward or downward excursion that can be safely carried out is stipulated. Divers breathe helium oxygen mixture maintaining oxygen partial pressure at
0.4 bars. Temperature is maintained around $26-28^{\circ} \mathrm{C}$ with a humidity of $70 \%$. Carbon dioxide generated is removed chemically using scrubbers similar to closed circuit anaesthesia machine. These vessels have a built-in open to sea area inside the hull called "moon pool" through which the bell is lowered in water (Fig. 1). They descend down into the sea in a diving bell for carrying out necessary tasks. Divers

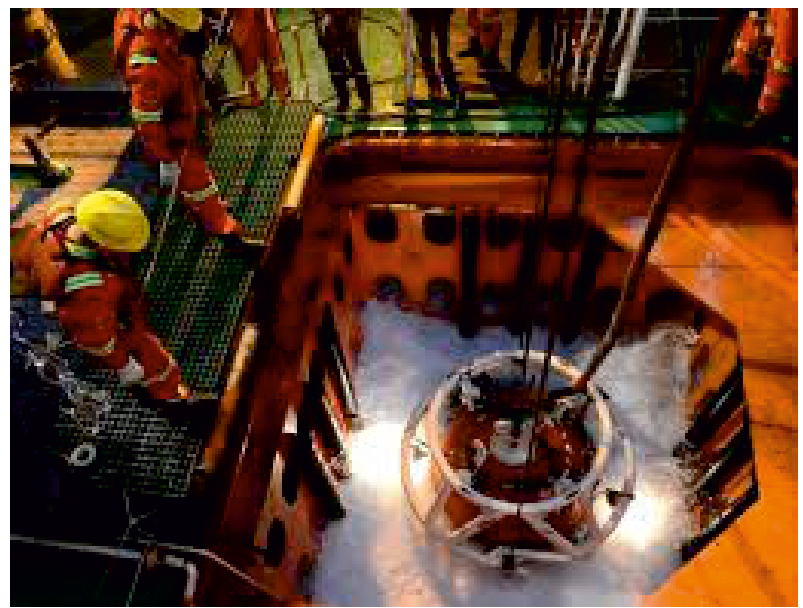

Figure 1. Diving bell being lowered from Monopol 
work in pairs. A diver goes out of the bell and works for 4-6 $\mathrm{h}$ and returns to the bell. Then the second diver goes out and continues working. Diver remaining in the bell is referred to as bell man who is expected to render assistance to the diver in water in an emergency situation. After working, the bell is lifted back to the diving vessel and the divers enter the habitat for rest. They are replaced by another pair of divers in the bell and the work continues. After 4-6 weeks of remaining under pressure in the habitat, divers are slowly decompressed back to surface at a thumb rule rate of $1 \mathrm{~h} / \mathrm{m}$, i.e. if the habitat pressure was equivalent to $60 \mathrm{~m}$ of sea water (msw), decompression would take $60 \mathrm{~h}$. This is called saturation diving.

In offshore, diving to first $20-25 \mathrm{~m}$ of depth is carried out using air and for depths below that saturation diving.

\section{INCIDENCE REPORT}

Multipurpose support vessels (MSV) are used for supporting work in an oil field. They are capable of air and saturation diving, firefighting, oil pollution control etc. Such a MSV operating in Mumbai offshore oil fields was engaged in removal of old anodes fitted on a platform. The depth of dive was $53 \mathrm{msw}$. The MSV had a "cross haul" bell launching system, i.e. although the bell was launched from the "moon pool" in the middle of the ship, it travelled laterally and then went down as if lowered from the ships' side. It was a three-man bell having $4.5 \mathrm{~m}^{3}$ volume, but in practice, two divers in saturation were used. Divers were breathing a $10 \%$ oxy-helium mixture $\left(10 \% \mathrm{O}_{2}\right.$ and $90 \% \mathrm{He}$ ). Bell was launched to $46 \mathrm{msw}$ and the diver locked out to work as per plan and reached the work location on the leg of the platform. The required cutting gear was lowered from the vessel to the depth and the diver set up the cutting gear on the job to commence work. Cutting produces a very bright flash which blinds the diving supervisor on his monitor screen. Supervisors therefore often switch off the diver's camera. Audio monitoring is continuous and breathing sound of the diver is an indication that everything is okay.

The anode was fitted with three stubs on the leg. The diver cut two top stubs and informed the diving supervisor accordingly. He relocated for final cut on bottom stub. At that position, visibility was poor and halfway through cutting he needed to change the burning rod. He did not notice a small "gas pocket" on the stub due to poor visibility. After changing the rod and striking it for the final cut, the gas pocket exploded with a big noise. Hearing the sound, the diving supervisor switched "on" the diver's camera. All he could see was the hand of the diver. He tried calling the diver repeatedly but there was no response.

When the gas pocket exploded, the diver fell down from his perch and soon went into a state of shock and lost consciousness. While falling down he managed to operate the valve on the helmet, changing his gas supply from on demand to a continuous flow. In the process he also managed to get a grip on a grout pipe on the platform leg at $66 \mathrm{msw}$. Due to the continuous supply of gas to the helmet, there was a static rattle on the communication radio; the diving supervisor could not ascertain whether the diver was breathing.

The diving supervisor immediately asked the second diver, referred to as bell man, to get out of the bell and rescue the stricken diver as is the normal rescue procedure. The bell man after hearing the explosion had also heard the frantic calling of the supervisor and was aware of emergency situation at hand. He dressed up and informed the supervisor that he was not getting adequate gas supply in his helmet and could not get out of the bell to swim towards the diver in distress.

The diving superintendent called the author at around 20:00 $\mathrm{h}$ and apprised him of the situation. At that time "air diving" was taking place on the same leg of the platform. A decision was taken to launch the "stand by" air diver who was geared for any emergency situation for air diving. Because of cross haul diving bell system, the air diver could follow the bell umbilical and descend in water. The plan was to follow the unconscious diver's umbilical from the bell and reach him. Air diver's umbilical was short and he could not reach the unconscious diver but could enter the bell. Once inside the bell, he discarded his air diving gear and donned the helmet from the bell. He was now breathing helium oxygen (heliox) mixture instead of air and a change in voice quality confirmed it.

The rescue diver soon managed to reach the unconscious diver. He reported that the free flow gas valve was open and breathing gas was flowing out of the diver's helmet and that there was no water in the helmet. He also reported that the diver was not responding. He pulled the unconscious diver to the bell and both were helped to enter the bell by the bell man. When his helmet was removed inside the bell, he was still unconscious.

As they splashed fresh water on his face he opened his eyes momentarily. The bell man reported to the supervisor that the diver was alive. The bell was secured as quickly as possible and hoisted back on the MSV. Once in the living chamber, the diver was connected to higher partial pressure (1.6 bar $\mathrm{PpO}_{2}$ ) heliox through built in breathing system (BIBS) called "treatment mix". Three sessions were used breathing this mix for $20 \mathrm{~min}$ followed by a $5 \mathrm{~min}$ break breathing habitat mix and he recovered his consciousness immediately.

There was a strong possibility that the rescue diver would go into hypothermia as he was not wearing a hot water suit. Hot water is circulated through the suit of the diver. This is a must for heliox dive. Helium has a high thermal conductivity. Even on surface, if a person breaths 
$80 \%$ helium and $20 \%$ oxygen mixture (80/20 heliox mix), he starts feeling cold in a very short time. Diver breathing heliox mixture underwater loses body heat very quickly due to breathing cold and dry inspired gas. Some heat loss also occurs from body surface in cold water. Air divers' 'wet suit" is not as thick as that worn by a saturation diver more so in tropical water. Air diver had breathed heliox mixture for almost half an hour without thermal support. There was no shivering. Rectal temperature was $36.4^{\circ} \mathrm{C}$. He was made to wear thermal clothing and covered with a duvet; environment control unit temperature was raised to $32^{\circ} \mathrm{C}$ and hot water bottles placed near his body. He was given plenty of sweet hot chocolate to drink. He recovered in a short span of time.

After a $24 \mathrm{~h}$ hold, saturation decompression was carried out and the diver was sent ashore for a thorough medical evaluation. Chest X-ray was reported as normal. Both ear drums were intact. Gas diffusion studies and high resolution computed tomography of the chest were normal. He was declared fit for diving and after resuming work as a diver for a while is now a saturation diving supervisor.

\section{DISCUSSION}

Cause of accident was explosion of a pocket of oxygen hydrogen mixture produced during cutting operations.

Oxy-arc cutting involves the use of large quantities of oxygen and generates hydrogen during the process. When the proportion of hydrogen to oxygen reaches a certain level, an explosive mixture is formed, which ignites when the arc, or a spark, reaches it. Gas pockets are formed when the shape of a structure being cut is such that bubbles of gas are trapped on their way to the surface and allowed to accumulate in sufficient quantity. Such spontaneous explosions of varying intensity occur at the cutting point. Ruptured tympanic membranes in ears, lung injuries and death have been recorded. Research has shown that there is enough hydrogen produced, during the time between making the rod 'hot' and striking the arc, to cause an explosion. An interval of $4 \mathrm{~s}$ was shown to be long enough to produce sufficient hydrogen to cause a serious explosion. Additional explosive or flammable substances on the surface or inside the object being cut e.g. hydrocarbons inside a pipe, paint or bituminous coatings, and some light alloy materials also contribute to the mechanism of blow back [1].

Safety of the rescue diver was the biggest risk taken in the operation. Initially it was planned that he would rescue the unconscious diver and then surface with requisite decompression stops in water or enter the bell and change over to breathing heliox mixture. But the rescue plan changed altogether when he changed over to breathing heliox from bell with new risks. He was dressed up as an air diver and then changed over to breathing heliox mixture using bell man's diving helmet. He was not wearing a "hot water" suit and was in an imminent danger of going into hypothermia. After rescue, a $24 \mathrm{~h}$ hold was considered necessary to stabilise the rescue and affected diver before commencing decompression.

Immobilisation of the bell man is explained by a polyvagal theory of adaptive reaction of the autonomic nervous system wherein when faced with an extreme situation, a person goes into "fight/flight/fright" situation. Either he develops immense strength to face the situation and concur it (fight), run away from scene (flight) or develops severe bradycardia leading to immobilization and unconsciousness (fright) [2].

\section{CONCLUSIONS}

The accident occurred in spite of following safety procedures as laid down by the industry [3]. A potential fatality was averted by quick action.

\section{REFERENCES}

1. International Marine Contractor's Association. 52, Grosvenor gardens, London SW1W OAV. Safety Flashes SF 05/04.

2. Porges SW. The polyvagal theory: new insights into adaptive reactions of the autonomic nervous system. Cleve Clin J Med. 2009; 76(Suppl. 2): S86-S90, doi: 10.3949/ccjm.76.s2.17, indexed in Pubmed: 19376991.

3. International Marine Contractor's Association. 52, Grosvenor gardens, London SW1W OAV. Oxy Arc Cutting D 003 Rev 1, 2001. 